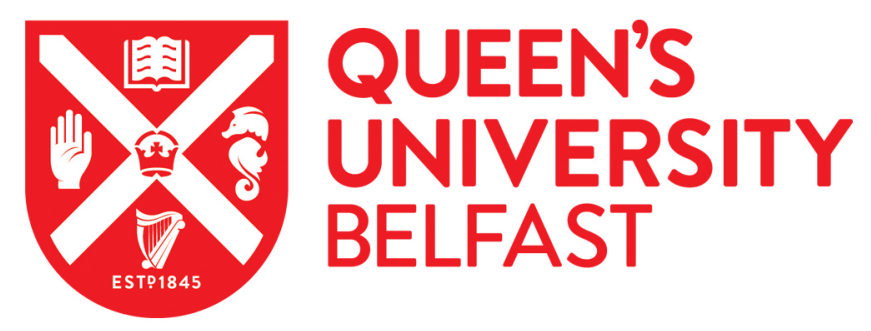

\title{
A phase I pharmacokinetic and pharmacodynamic study of the oral mitogen-activated protein kinase kinase (MEK) inhibitor, WX-554, in patients with advanced solid tumours

\author{
Jamieson, D., Griffin, M., Sludden, J., Drew, Y., Cresti, N., Swales, K., Merriman, M., Allen, R., Bevan, P., \\ Buerkle, M., Mala, C., Coyle, V., Rodgers, L., Dean, E., Greystoke, A., Banerji, U., Wilson, R., Evans, J., \\ Anthoney, A., ... Plummer, R. (2016). A phase I pharmacokinetic and pharmacodynamic study of the oral \\ mitogen-activated protein kinase kinase (MEK) inhibitor, WX-554, in patients with advanced solid tumours. \\ European Journal of Cancer, 68. https://doi.org/10.1016/j.ejca.2016.08.026 \\ Published in: \\ European Journal of Cancer
}

Document Version:

Peer reviewed version

Queen's University Belfast - Research Portal:

Link to publication record in Queen's University Belfast Research Portal

\begin{abstract}
Publisher rights
(C) 2016 Elsevier, this manuscript is distributed under a Creative Commons Attribution-NonCommercial-NoDerivs License

(https://creativecommons.org/licenses/by-nc-nd/4.0/), which permits distribution and reproduction for non-commercial purposes, provided the author and source are cited.
\end{abstract}

\section{General rights}

Copyright for the publications made accessible via the Queen's University Belfast Research Portal is retained by the author(s) and / or other copyright owners and it is a condition of accessing these publications that users recognise and abide by the legal requirements associated with these rights.

\section{Take down policy}

The Research Portal is Queen's institutional repository that provides access to Queen's research output. Every effort has been made to ensure that content in the Research Portal does not infringe any person's rights, or applicable UK laws. If you discover content in the Research Portal that you believe breaches copyright or violates any law, please contact openaccess@qub.ac.uk. 
A Phase I pharmacokinetic and pharmacodynamic study of the oral MEK inhibitor, WX-554, in patients with advanced solid tumours.

David Jamieson ${ }^{a}$, Melanie J Griffin ${ }^{a}$, Julieann Sludden ${ }^{a}, Y_{\text {Yvette Drew }}{ }^{\mathrm{a}, \mathrm{b}}$, Nicola Cresti ${ }^{\mathrm{b}}$, Karen Swales ${ }^{c}$, Mark Merriman ${ }^{d}$, Rodger Allen ${ }^{d}$, Paul Bevan $^{\mathrm{e}}$, Markus Buerkle ${ }^{\mathrm{e}}$, Carola Mala ${ }^{\mathrm{e}}$, Vicky Coyle $^{f}$, Lisa Rodgers ${ }^{\mathrm{g}}$, Emma Dean ${ }^{\mathrm{i}}$, Alastair Greystoke ${ }^{\mathrm{a}, \mathrm{b}}$, Udai Banerji ${ }^{\mathrm{c}}$, Richard H Wilson ${ }^{\mathrm{f}}$, TR Jeffry Evans ${ }^{\mathrm{g}}$, Alan Anthoney ${ }^{\mathrm{h}}$, Malcolm Ranson, Alan V Boddy ${ }^{\mathrm{a}}$, Ruth Plummer ${ }^{\mathrm{a}, \mathrm{b}^{*}}$

a. Northern Institute for Cancer Research, Paul O'Gorman Building, Medical School, Newcastle University, Newcastle upon Tyne, NE2 4HH, UK.

b. Northern Centre for Cancer Care, Newcastle Freeman Hospital, Newcastle upon Tyne, NE7 7DN, UK.

c. Cancer Research UK Cancer Therapeutics Unit, The Institute of Cancer Research, London, UK

d. UCB, 216 Bath Road, Slough, SL1 4EN, UK.

e. WILEX AG, Grillparzerstr. 18, 81675 Munich, Germany.

f. Centre for Cancer Research and Cell Biology, Queen's University Belfast, Belfast, UK and Northern Ireland Cancer Center, Belfast City Hospital, Belfast, UK

g. Beatson West of Scotland Cancer Centre, University of Glasgow, Glasgow, G12 OYN, UK.

h. St. James's Institute of Oncology, Beckett Street, Leeds, LS9 7TF, UK.

i. The Christie NHS Foundation Trust / The University of Manchester, Manchester, M20 4BX, UK.

*Corresponding author and reprint requests:

Ruth Plummer

Northern Institute for Cancer Research

Medical School

University of Newcastle upon Tyne

NE2 4HH

Phone: +44 (0) 1912084414

Email: ruth.plummer@ncl.ac.uk 


\section{Abstract}

Purpose

We performed a multi-centre phase I study to assess the safety, pharmacokinetics and pharmacodynamics of the orally available small molecule MEK $1 / 2$ inhibitor WX-554, and to determine the optimal biological dose for subsequent trials.

Experimental design

Patients with treatment-refractory, advanced solid tumours, with adequate performance status and organ function were recruited to a dose escalation study in a standard $3+3$ design. The starting dose was 25 mg orally once weekly with toxicity, pharmacokinetic (PK) and pharmacodynamics (PD) guided dose escalation with potential to explore alternative schedules.

Results

Forty-one patients with advanced solid tumours refractory to standard therapies and with adequate organ function were recruited in 8 cohorts up to doses of $150 \mathrm{mg}$ once weekly and 75 mg twice weekly. No dose limiting toxicities (DLTs) were observed during the study and a Maximum Tolerated Dose (MTD) was not established. The highest dose cohorts demonstrated sustained inhibition of ERK phosphorylation in PBMC peripheral blood mononuclear cells following ex vivo phorbol 12-myristate 13-acetate (PMA) stimulation. There was a decrease of $70 \pm 26 \%$ in mean phosphorylated (p)ERK in C1 Day 8 tumour biopsies when compared with pre-treatment tumour levels in the $75 \mathrm{mg}$ twice a week cohort. Prolonged stable disease (> 6 months) was seen in 2 patients, one with cervical cancer and one with ampullary carcinoma. 
Conclusions

WX-554 was well tolerated and an optimal biological dose was established for further investigation in either a once or twice weekly regimens. The recommended phase 2 dose is 75 mg twice weekly.

Keywords:

MEK inhibitor, Phase I, Pharmacodynamics, Pharmacokinetics, Optimal Biological Dose.

Acknowledgements

We thank the staff of the Institute for Cancer Research and the Northern Centre for Cancer Care, Newcastle; Royal Marsden Hospital and Institute of Cancer Research, London; Belfast City Hospital; Beatson West of Scotland Cancer Centre, Glasgow; St James' Hospital, Leeds; The Christie Hospital and CRUK Manchester Institute, Manchester; and Wilex AG. Above all, we particularly thank our patients, their families and friends for their support and participation in this trial. We acknowledge the funding to the centres of the UK Experimental Cancer Medicine Centre Network by Cancer Research UK and the UK Departments of Health.

Financial support for this study was provided by Wilex AG. 
Introduction

The RAS/RAF/MEK/ERK pathway is one of the major signal transduction pathways that controls cell proliferation and survival [1]. In preclinical studies, constitutive activation of the pathway has been shown to promote cellular transformation to an oncogenic phenotype [2]. Nearly a third of all cancers have a constitutively-active MAPK pathway and numerous upstream mutations in and/or over-expression of growth factor receptors, such as RAS and RAF, lead to activation of the MEK pathway. Clinical development of MEK inhibitors has focused to date on BRAF mutated disease including malignant melanoma, papillary thyroid cancer, ovarian cancer and colorectal cancer [3].

MEK inhibitors are efficacious in multiple xenograft models where the MAPK pathway is activated $[4,5]$. Moreover, MEK inhibitors in clinical trials have demonstrated anti-tumour activity as monotherapy [6], ]as well as a synergistic or additive efficacy with cytotoxics and other targeted drugs, particularly BRAF inhibitors [7-9].

WX-554 is an oral small molecule allosteric inhibitor targeting mitogen-activated protein kinase kinase (MEK1 and MEK2) with an estimated $\mathrm{IC}_{50}$ of $4.7 \mathrm{nM}$ and $10.7 \mathrm{nM}$ respectively. A previous dose escalation study in healthy volunteers showed prolonged inhibition of MEK for over 72 hours following a single dose at all dose levels explored, with minimal toxicity encountered at doses $<100 \mathrm{mg}$, and a maximum tolerated dose was not reached. Bioavailability was good with an estimated absorption of $>80 \%$ and minimal impact of food on absorption. This study is the first in advanced cancer patients and aimed to define a safe, 
well-tolerated and pharmacodynamically-active oral dosing regimen of WX-554 to be taken forward into Phase II studies. 
Methods

\section{Study design}

A Phase I, open-label, dose-escalation study to investigate the safety, pharmacokinetic profile, pharmacodynamic activity and anti-tumour activity of the MEK inhibitor WX-554 was undertaken in five clinical centres in the United Kingdom between March 2012 and March 2014 (EudraCT No: 2011-003408-19). All patients gave written informed consent prior to undergoing any study-related procedures and the study was approved by an independent ethics committee and by the study centres. The study was performed according to ICH-GCP guidelines. The primary objective of the study was to determine the optimum biological dose (OBD) and the MTD, or the MTD alone if observed before the OBD. Eligible patients recruited were age $\geq 18$ years old with advanced, metastatic solid tumours for whom no effective standard therapy was available. Patients had to have an Eastern Cooperative Oncology Group Performance Status (ECOG PS) less than or equal to 2, a life expectancy of more than three months and adequate organ function. Additional exclusion criteria included previous treatment with a MEK inhibitor, untreated or unstable brain metastases; past history of retinal vein occlusion, intraocular pressure $>21 \mathrm{~mm} \mathrm{Hg}$ or patients considered at risk of retinal vein thrombosis. Slit lamp examinations were performed when clinically indicated at any point over the course of the study.

Sequential cohorts in a $3+3$ design of at least 3 and up to 6 patients were enrolled, with each evaluable patient receiving at least one cycle of WX-554. The initial dose and schedule (informed by the findings of the healthy volunteers study) was $25 \mathrm{mg}$ orally on Days 1,8 and 15 of a 21-day cycle, and in the absence of DLTs, doses could be escalated by up to $100 \%$ between cohorts until the OBD and/or MTD was reached. Tumour burden was assessed 
radiologically prior to therapy and every 2 cycles thereafter according to RECIST 1.1 [10]. Patients could continue to receive WX-554 until disease progression or withdrawal due to toxicity.

Patients were seen weekly whilst on study and toxicity graded for severity based on the National Cancer Institute Common Terminology Criteria for Adverse Events version 4.03 ( $\mathrm{NCl} \mathrm{CTCAE} \mathrm{v4.03).} \mathrm{Full} \mathrm{blood} \mathrm{count,} \mathrm{routine} \mathrm{biochemistry,} \mathrm{liver} \mathrm{and} \mathrm{coagulation} \mathrm{profile} \mathrm{were}$ checked weekly during cycle 1 and at the start of each subsequent cycle. The following were considered DLTs ; Grade 3/4 non-haematologic toxicity, excluding inadequately treated nausea, vomiting or diarrhoea; $\geq$ Grade 3 neutropenia of clinically significant duration, or associated with fever; Grade 4 thrombocytopenia or thrombocytopenia with clinically significant bleeding; a delay in a scheduled dose of WX-554 of $>14$ days due to toxicity. If a single DLT event was observed, subsequent dose escalations were not to exceed $33 \%$ of the previous dose. If two or more DLTs occurred in a given cohort of up to 6 patients, the next lower dose level was declared the MTD. All dose escalation steps and dose schedule recommendations were made by a Cohort Review Committee (CRC) who reviewed all available adverse events, pharmacokinetics, pharmacodynamics and other relevant patient data. The CRC could recommend exploration of alternative doses and schedules of WX-554 to maximise target inhibition with acceptable tolerability.

The OBD was defined as the highest dose to attain maximal target inhibition, utilising a validated PD assessment of pERK in PBMCs and tumour biopsies at a tolerable dose. 


\section{Pharmacodynamic assessments}

Phosphorylation of ERK1/ERK2 was measured in circulating PBMCs following ex-vivo incubation with PMA. An $8 \mathrm{ml}$ volume of whole blood was collected into a CPT vacutainer (BD, Oxford, UK) containing Sodium-Heparin during cycle 1 on day 1 and day 8 at $0,1,2,4$, 6 , and 24 hours relative to the time of drug administration. Additional pre-dose samples were taken at day 15 and at day 1 of subsequent cycles. The tubes were centrifuged at 1,638g for 20 minutes to separate the PBMCs and plasma from other cellular contents and this fraction was decanted into a $15 \mathrm{ml}$ Falcon tube (BD, Oxford, UK) for incubation with 500 nM PMA (Sigma, Dorset, UK) for 20 minutes at $37^{\circ} \mathrm{C}$. After two PBS washes the cells were pelleted and re-suspended in $1 \mathrm{ml}$ of a lysis buffer containing $10 \mu \mathrm{g} / \mathrm{ml}$ leupeptin, $10 \mu \mathrm{g} / \mathrm{ml}$ pepstatin, $100 \mu \mathrm{M}$ phenylmethanesulfonylfluoride (PMSF), $3 \mu \mathrm{g} / \mathrm{ml}$ aprotinin, $2.5 \mathrm{mM}$ sodium pyrophosphate, $1 \mathrm{mM}$ sodium orthovanadate, $6 \mathrm{M}$ Urea, $1 \mathrm{mM}$ ethylenediaminetetraacetic acid (EDTA), $0.5 \%$ Triton $X 100,5 \mathrm{mM}$ sodium fluoride in phosphate buffered saline (PBS) (all from Sigma, Dorset, UK), pH 7.4. Lysis was carried out for 15 minutes on ice and lysate was store at $-20^{\circ} \mathrm{C}$ prior to analysis.

Phospho-ERK in the PBMC lysates was measured by a commercially available ELISA kit according to manufacturer's instructions (R\&D Systems, Oxford, UK).

Absorbance was read at $450-590 \mathrm{~nm}$ and the concentration interpolated from a $2^{\text {nd }}$ order polynomial curve over the range $20,10,5,3,2,1$ and $0.5 \mathrm{ng} / \mathrm{ml}$ pERK. In parallel the protein concentration of the lysates was determined by the BCA assay (Thermo Scientific, Cramlington, UK). The final pERK1/2 concentration of the lysates was expressed as the ratio of the C1D1 sample after correcting for protein concentration. 
Total and phosphorylated AKT, GSK3 $\beta$, P70S6K and ERK $1 / 2$ in lysates from frozen tumour biopsies were measured using the electrochemiluminescent assays validated to good clinical practice standards on the Meso Scale Discovery (MSD) platform (MSD, Rockville, USA). Phosphorylated residues detected were Ser473 AKT, Ser9 GSK3 $\beta$, Thr421/Ser424 P70S6K, Thr202/204 ERK1 and Thr185/187 ERK2. Protein concentrations of the tumour lysates were determined by BCA assay prior to analysis to allow known concentrations of lysate to be analysed. Values of phosphorylated protein were expressed as a percentage of the phosphorylated protein levels before administration of WX-554, normalised to total protein (expressed as a percentage of pre-administration total protein levels) for each analyte.

\section{Pharmacokinetic Studies}

The concentration of WX-554 in plasma was measured in all patients in cycle 1 on day 1 and day 8 at $0,1,2,4,6,8,10$ and 24 hours, and before dosing on day 1 of each subsequent cycle. Measurement was by an LC-MS/MS method developed and validated by Wilex AG (Munich, Germany) on an API 3200 with Shimadzu LC-10ADvp HPLC. After solid phase extraction of $60 \mu \mathrm{l}$ plasma on an Oasis WCX plate and elution with $2 \times 250 \mu \mathrm{l} \%$ formic acid in methanol, the samples were evaporated to dryness and re-suspended in $100 \mu \mathrm{l}$ acetonitrile/methanol (25/75). A $10 \mu \mathrm{l}$ volume (equivalent of $6 \mu \mathrm{l}$ plasma) was injected onto an Atlantis HILIC, $2.1 \times 50 \mathrm{~mm}, 3 \mu \mathrm{m}$ column (Waters, Eschborn, Germany). Mobile phase was: A, $10 \mathrm{mM}$ ammonium formate, $\mathrm{pH} 3.8 /$ acetonitrile $(95 / 5 \mathrm{v} / \mathrm{v})$ and $\mathrm{B}, 10 \mathrm{mM}$ ammonium formate, $\mathrm{pH} 3.8 /$ acetonitrile $(5 / 95 \mathrm{v} / \mathrm{v})$. Elution occurred over a 2 minute gradient from 10:90 A:B to 60:40 A:B. WX-554 was eluted at 1.5 minutes. Upper and lower limits of 
quantification were 1000 and $1 \mathrm{ng} / \mathrm{ml}$ respectively. Both intra-assay and inter-assay coefficient of variation (CV) were $<4 \%$ for all QC samples analysed.

Pharmacokinetic parameters were calculated from drug concentrations in plasma vs. time curves using Phoenix WinNonlin version 6.2 (Certara, Princeton, USA) non-compartmental analysis. 


\section{Results}

Patient demographics are shown in table 1 . A total of 41 patients were recruited into the study. With a median age of 63 years (range 36-77 years), the population was mainly male (68\%) and colorectal cancer was the most common solid tumour type. One patient developed fatal bronchopneumonia before dosing with WX-554 and an additional patient was recruited to the study. Weekly dosing (QWK) was explored in 5 cohorts with doses from 25 to 150 and twice-weekly dosing (BIS) in 3 cohorts with doses of 25 to $75 \mathrm{mg}$ (Table S1).

Safety

WX-554 was generally well tolerated, with the majority of adverse reactions being CTCAE Grade 1 or 2 . A total of 489 adverse events were recorded with each of the 41 participants experiencing at least one $A E$ and 33 (80.5\%) had AEs considered to be related to WX-554. A total of 47 adverse event resulting in 30 incidents of dose delay or reduction were recorded in 12 patients over the course of the study. Of these 47 incidents 18 (38.3\%) were considered to be possibly or probably related to study drug. Incidence of dose delay or reduction did not correlated with dose (Figure S1). Fatigue and diarrhoea were the most common adverse reactions followed in order of decreasing frequency by skin reactions, decreased appetite and nausea (Table 2). When evaluated by cohort (Table S2) the incidence of treatment-related AE generally increased with dose and no clear differences in the incidence of toxicity were observed between the $75 \mathrm{mg}$ BIS and $150 \mathrm{mg}$ QWK schedules. However, fatigue was more common in the 75 mg BIS cohort ( $78 \%$ compared with $57 \%$ in the $150 \mathrm{mg}$ QWK cohort) with and diarrhoea more frequent in the $150 \mathrm{mg}$ QWK than in the 
$75 \mathrm{mg}$ BIS (71 and $22 \%$ respectively). No dose-limiting toxicities were recorded during the study and the MTD was not reached.

In the absence of significant toxicity pharmacokinetic and pharmacodynamic data was used to inform dose decision making. PK data closely mirrored that in healthy volunteers, and PK/PD modelling suggested that a longer duration of maximal inhibition might be achieved with twice weekly dosing. Therefore from the $75 \mathrm{mg}$ dose level, the twice weekly dosing was explored in parallel, for safety reasons this was at one cumulative dose level behind the weekly dosing.

Four potentially drug-related serious adverse events (SAEs) were observed and these all occurred at higher doses. These were sigmoid bowel perforation at a site of known disease (75 mg QWK at day 15), Grade 3 transaminitis (100mg QWK at day 47), Grade 4 anaemia (150 mg QWK at day 63) and Grade 2prolongation of QTc interval (75 mg BIS at day 15). Treatment was discontinued in the patients with bowel perforation and prolonged QTc; the other patients were re-challenged at a lower dose and tolerated treatment well. Despite these events being either not definitively related to the study drug or occurring outside the formal DLT window each of these respective cohorts was expanded to 6 evaluable patients to ensure safety of any recommended dose.

Pharmacodynamic effects

Inhibition of ERK phosphorylation in ex vivo PMA-stimulated PBMCs was observed from the first dose level explored (Figure 1). Within the cohorts treated once weekly, maximum inhibition of ERK phosphorylation was seen at 4 or 6 hours, with recovery towards basal 
levels seen at day 2 and 8 (Figure 1a). In cohorts 1, 2, 3 \& 5, the mean maximum inhibition at 6 hours post administration on day 8 , was $73 \pm 5 \%$. The average degree of inhibition seen in the day 8 pre administration samples was $2 \pm 18 \%$. In contrast, at the highest dose explored (150 mg QWK), the maximal degree of inhibition was $92 \%$ and residual inhibition was observed in the day 8 pre administration sample (69\%). In the twice weekly cohorts there was a clear dose/PD relationship in the inhibition of ERK phosphorylation (Figure 1b). Following administration of $75 \mathrm{mg}$ BIS pERK was inhibited $60 \%$ in the day 8 pre samples and $70 \%$ in the 6 hour samples at day 8.

Five paired tumour biopsies were available in cohort 8 (75 mg twice weekly), taken at the time of screening and at day 8. Biopsies were taken from liver metastases in 3 of the patients with primary $\mathrm{CRC}$, pancreatic or cholangiocarcinoma; from right axillary lymph node from a separate patient with cholangiocarcinoma; and from a colorectal lung metastasis. Following homogenisation, tumour lysates were analysed using MSD electrochemiluminescent assays for the modulation of kinase signalling pathways. There was no change in the phosphorylation of AKT, GSK3 $\beta$ or P70S6K (all used as markers of PI3K pathway inhibition), between the pre-treatment and C1D8 biopsies (Figures 2a, b \&c).

In contrast, pERK signal was lower in $5 / 5$ paired biopsies with a median decrease of $68 \%$ (range, 30-95\%) as a ratio of total ERK at day 8 of cycle one compared with the screening biopsy. 


\section{Pharmacokinetics}

Pharmacokinetic parameters in all the cohorts are shown in Table 3. Mean exposure for each cohort over 24 hours following administration of cycle 1 on day 1 is shown in Figure 3. Individual concentration-time curves for each patient on day 1 and day 8 are shown in Figure S2. The drug appeared to be well absorbed with an average Tmax of 4.9 hours independent of dose with a mean half-life of 28 hours following all doses on day 1 . Dose proportionality was observed between 25 and $75 \mathrm{mg}$ administration, however, the once weekly administration of $150 \mathrm{mg}$ resulted in greater variation in AUC. The mean concentration at 24 hours in the 150 QWK cohort was greater than the mean peak concentration in the 100 QWK cohort (figure 3a), and this was reflected in the degree of pERK inhibition at the 24 hour time point of the 150 QWK cohort also being greater than that seen in the peak inhibition of the 100 QWK cohort (figure 1a).

\section{Efficacy}

34 patients completed $\geq 6$ weeks of dosing with WX-554 and were eligible for response assessment. No objective responses were observed, however 20 (59\%) of participants had stable disease and two patients (6\%) had prolonged disease stabilisation.

A 54 year old woman with cervical cancer and locally advance pelvic disease had disease control for 10 cycles (over 30 weeks) at a dose of $75 \mathrm{mg}$ QWK. Recruitment followed three previous lines of therapy including chemorad with cisplatin, five cycle of carboplatin and paclitaxel, and participation in a phase I trial of an IGFR inhibitor. A second case of prolonged stable disease was observed in a 66 year old woman with ampullary carcinoma 
and lung metastases, previously treated with Gemcitabine and Cisplatin, who had controlled disease for 16 cycles (i.e. over 48 weeks) at a dose of $75 \mathrm{mg}$ BIS. 


\section{Discussion}

This study shows that WX-554 is very well tolerated, with favourable pharmacokinetic characteristics, and that pharmacodynamically-active concentrations are achievable. No definite dose-limiting toxicities were observed and therefore a MTD was not identified. However, a dosing regimen of $75 \mathrm{mg}$ BIS for an expansion cohort was identified as an optimal biological dose (OBD) based on maximal observed inhibition of ERK phosphorylation in PMA-stimulated PBMCs and 70\% decrease in PERK/ERK in tumour lysates at the day 8 trough. While the maximum pERK inhibition in PBMCs was greater in the $150 \mathrm{mg}$ cohort than in the $75 \mathrm{mg}$ twice weekly cohort it was felt that a more sustained inhibition was seen in the $75 \mathrm{mg}$ twice weekly cohort. As well as the more sustained pERK inhibition it was felt that the PK properties of the $75 \mathrm{mg}$ twice weekly schedule were preferable given the greater variation in exposure in the $150 \mathrm{mg}$ cohort compared to the others. The intermittent weekly or BIS schedules had been identified as providing the optimal therapeutic window in preclinical studies. Although other schedules might also be beneficial, this regimen is supported by the sustained pharmacodynamic effect.

The use of MEK inhibitors in cancer chemotherapy has been the subject of clinical research for more than 10 years. Initial studies suffered from poor efficacy, which has been attributed to a lack of selection of patients with demonstrated oncogenic lesions of the MAPK pathway, poor pharmacokinetic properties and narrow therapeutic window, leading to dose reduction and treatment interruptions [11]. More recently, development of both a new generation of MEK inhibitors with better PK properties and enrichment for patients more likely to benefit has led to successes in the clinical utility of MEK inhibition. This has culminated in the approval of trametinib as a first line option in the treatment of BRAF mutated melanoma $[6,8]$ and of cobimetinib for use in combination with vemurafenib for 
the treatment of adult patients with unresectable or metastatic melanoma with a BRAF V600 mutation [12].

However, the introduction of kinase inhibitors and biological agents targeting kinase signalling pathways has led to the observation of new toxicities in oncology clinics, particularly the skin and ocular problems resulting from inhibition of the MAPK pathway. The toxicity profile of WX-554 had similarities to that of other MEK inhibitors, with fatigue, diarrhoea, and dermatological reactions being the most frequent adverse reactions [13-18]. However, rash was not as frequently seen as with other MEK inhibitors, with any rash being seen in $27.5 \%$ of participants and maculo-papular rashes in just three participants $(7.5 \%)$. Ocular toxicity was not reported in any patients. The case of grade 4 anaemia in a patient treated with the highest dose was possibly drug related and the patient recovered and continued on study at a reduced dose. It is unknown at present if this is an off target effect of the drug though this must be considered a possibility in light of haematotoxicity not being seen with other MEK inhibitors. No severe anaemia was seen at the lower dose recommended for subsequent development. The likelihood that other adverse reactions seen during MEK inhibitor therapy are related to mechanism of action means that clinical regimens will have to include development of novel management protocols. Using quality of life measures, trametinib is reported to be better tolerated than standard chemotherapy [19], although this was in an open label study and may not reflect tolerance of prolonged therapy.

The mean half-life of 28 hours of WX-554 is longer than that of most MEK inhibitors currently undergoing clinical investigations, with the exception of trametinib [15] and the dual RAF/MEK inhibitor RO5126766 [18]. This long half-life permitted the investigation of 
both weekly and then twice weekly dosing schedules. When comparing the two cohorts given a cumulative weekly dose of $150 \mathrm{mg}$ ( $150 \mathrm{QWK}$ and $75 \mathrm{BIS}$ ), the $\mathrm{AUC}_{24 \mathrm{~h}}$ was proportionally greater than expected in the 150 QWK cohort compared to the 75 BIS cohort on both day $1(993.0 \pm 492.1 \mathrm{~h} * \mathrm{ng} / \mathrm{ml}$ and $276.0 \pm 127.9 \mathrm{~h} * \mathrm{ng} / \mathrm{ml}$ respectively) and day 8 (1129.8 $\pm 544.7 \mathrm{~h} * \mathrm{ng} / \mathrm{ml}$ and $320.4 \pm 150.7 \mathrm{~h} * \mathrm{ng} / \mathrm{ml}$ respectively). While this greater exposure with the once weekly schedule was not associated with a higher incidence of adverse events, there was no indication that it conferred greater efficacy and the inhibition of pERK phosphorylation appeared to be less sustained than that observed in the $75 \mathrm{mg}$ BIS cohort.

Numerous other early phase clinical trials have reported modulation of $p E R K$ in surrogate and tumour tissues following administration of MEK inhibitors [13-15, 20]. However, differences in assays, tissues and time points used make direct comparisons problematic. It is not known if the magnitude of the sustained pERK inhibition in a surrogate tissue correlates with either efficacy or mechanism-related toxicity. However, the magnitude of inhibition seen in the paired tumour biopsies indicates on target inhibition. No objective responses were observed in this heavily pre-treated population and any demonstration of efficacy must be determined in subsequent phase II and phase III trials. The lack of efficacy in this heavily pre-treated population may be partially attributable to lack of selection based on mutational analysis. Phase II and III trials of single agent trametinib have suggested efficacy in patients with BRAF-mutated melanoma who had not received previous BRAF inhibitor therapy [6] but not in those patients resistant to BRAF inhibition. In contrast, a series of phase II studies of other MEK inhibitors have shown limited evidence of efficacy in numerous settings, including treatment of cancers with high known incidence of 
dysregulated MAPK signalling [21-25] and selection of individuals with known BRAF-mutated tumours [26]. It is, therefore, likely that this class of agents will be used in rationally chosen combination therapy. Combination therapy with trametinib/dabrafenib and cobimetinib/vemurafenib for the treatment of BRAF-mutation positive melanoma has been shown to improve overall survival, and both these combinations are now licensed $[8,12$, 27]. It has been suggested that resistance to MEK inhibition may occur via up regulation of AKT signalling and that combination therapy with both MEK and PI3K inhibitors may be beneficial $[24,26]$, and investigations into this combination therapy continue [28]. The use of MEK inhibitors in combination with docetaxel has been investigated in phase II studies in melanoma [29] and NSCLC with indications that KRAS mutant NSCLC may be sensitive to the combination [30] and a phase III trial is underway to test the efficacy of the combination [31]. This Phase I study will inform the further development of WX-554 in phase II trials as a single agent and in additional Phase 1 combinatorial trials. It shows how preclinical data and modelling in conjunction with PK and PD can be used to help guide an OBD. WX-554 is well tolerated at pharmacologically active doses with an attractive once or twice weekly dosing schedule and so would be an ideal candidate for combination studies. 
Conflict of interest statement:

P Bevan, M Buerkle and Carola Mala were employees of Wilex AG who were developing WX554 during the study. Mark Merriman and Rodger Allen are employees of UCB who now own the rights for further development of WX-554. 


\section{References}

[1] Roberts PJ, Der CJ. Targeting the Raf-MEK-ERK mitogen-activated protein kinase cascade for the treatment of cancer. Oncogene. 2007;26:3291-310.

[2] Mansour SJ, Matten WT, Hermann AS, Candia JM, Rong S, Fukasawa K, et al. Transformation of mammalian cells by constitutively active MAP kinase kinase. Science. 1994;265:966-70.

[3] Garnett MJ, Marais R. Guilty as charged: B-RAF is a human oncogene. Cancer Cell. 2004;6:313-9.

[4] Hoeflich KP, O'Brien C, Boyd Z, Cavet G, Guerrero S, Jung K, et al. In vivo Antitumor Activity of MEK and Phosphatidylinositol 3-Kinase Inhibitors in Basal-Like Breast Cancer Models. Clin Cancer Res. 2009;15:4649-64.

[5] Yeh TC, Marsh V, Bernat BA, Ballard J, Colwell H, Evans RJ, et al. Biological characterization of ARRY-142886 (AZD6244), a potent, highly selective mitogen-activated protein kinase kinase 1/2 inhibitor. Clin Cancer Res. 2007;13:1576-83.

[6] Flaherty KT, Robert C, Hersey P, Nathan P, Garbe C, Milhem M, et al. Improved survival with MEK inhibition in BRAF-mutated melanoma. N Engl J Med. 2012;367:107-14.

[7] Jänne PA, Shaw AT, Pereira JR, Jeannin G, Vansteenkiste J, Barrios CH, et al. Selumetinib plus docetaxel for KRAS-mutant advanced non-small-cell lung cancer: a randomised, multicentre, placebo-controlled, phase 2 study. Lancet Oncol. 2013;14:38-47.

[8] Long GV, Stroyakovskiy D, Gogas H, Levchenko E, de Braud F, Larkin J, et al. Combined BRAF and MEK inhibition versus BRAF inhibition alone in melanoma. N Engl J Med. 2014;371:1877-88.

[9] Robert C, Karaszewska B, Schachter J, Rutkowski P, Mackiewicz A, Stroiakovski D, et al. Improved overall survival in melanoma with combined dabrafenib and trametinib. N Engl J Med. 2015;372:309.

[10] Eisenhauer EA, Therasse P, Bogaerts J, Schwartz LH, Sargent D, Ford R, et al. New response evaluation criteria in solid tumours: revised RECIST guideline (version 1.1). Eur J Cancer.

2009;45:228-47.

[11] Samatar AA, Poulikakos PI. Targeting RAS-ERK signalling in cancer: promises and challenges. Nat Rev Drug Discov. 2014;13:928-42.

[12] Larkin J, Ascierto PA, Dreno B, Atkinson V, Liszkay G, Maio M, et al. Combined vemurafenib and cobimetinib in BRAF-mutated melanoma. N Engl J Med. 2014;371:1867-76.

[13] Adjei AA, Cohen RB, Franklin W, Morris C, Wilson D, Molina JR, et al. Phase I pharmacokinetic and pharmacodynamic study of the oral, small-molecule mitogen-activated protein kinase kinase 1/2 inhibitor AZD6244 (ARRY-142886) in patients with advanced cancers. J Clin Oncol. 2008;26:2139-46.

[14] Cohen RB, Aamdal S, Nyakas M, Cavallin M, Green D, Learoyd M, et al. A phase I dose-finding, safety and tolerability study of AZD8330 in patients with advanced malignancies. Eur J Cancer. 2013;49:1521-9.

[15] Infante JR, Fecher LA, Falchook GS, Nallapareddy S, Gordon MS, Becerra C, et al. Safety, pharmacokinetic, pharmacodynamic, and efficacy data for the oral MEK inhibitor trametinib: a phase 1 dose-escalation trial. Lancet Oncol. 2012;13:773-81.

[16] Leijen S, Middleton MR, Tresca P, Kraeber-Bodere F, Dieras V, Scheulen ME, et al. Phase I doseescalation study of the safety, pharmacokinetics, and pharmacodynamics of the MEK inhibitor RO4987655 (CH4987655) in patients with advanced solid tumors. Clin Cancer Res. 2012;18:4794805.

[17] Lorusso PM, Adjei AA, Varterasian M, Gadgeel S, Reid J, Mitchell DY, et al. Phase I and pharmacodynamic study of the oral MEK inhibitor $\mathrm{Cl}-1040$ in patients with advanced malignancies. J Clin Oncol. 2005;23:5281-93.

[18] Martinez-Garcia M, Banerji U, Albanell J, Bahleda R, Dolly S, Kraeber-Bodere F, et al. First-inhuman, phase I dose-escalation study of the safety, pharmacokinetics, and pharmacodynamics of RO5126766, a first-in-class dual MEK/RAF inhibitor in patients with solid tumors. Clin Cancer Res. 2012;18:4806-19. 
[19] Schadendorf D, Amonkar MM, Milhem M, Grotzinger K, Demidov LV, Rutkowski P, et al. Functional and symptom impact of trametinib versus chemotherapy in BRAF V600E advanced or metastatic melanoma: quality-of-life analyses of the METRIC study. Ann Oncol. 2014;25:700-6. [20] Weekes CD, Von Hoff DD, Adjei AA, Leffingwell DP, Eckhardt SG, Gore L, et al. Multicenter phase $i$ trial of the mitogen-activated protein kinase 1/2 inhibitor BAY 86-9766 in patients with advanced cancer. Clin Cancer Res. 2013;19:1232-43.

[21] Bekaii-Saab T, Phelps MA, Li X, Saji M, Goff L, Kauh JSW, et al. Multi-institutional phase II study of selumetinib in patients with metastatic biliary cancers. J Clin Oncol. 2011;29:2357-63.

[22] Bennouna J, Lang I, Valladares-Ayerbes M, Boer K, Adenis A, Escudero P, et al. A Phase II, openlabel, randomised study to assess the efficacy and safety of the MEK1/2 inhibitor AZD6244 (ARRY142886) versus capecitabine monotherapy in patients with colorectal cancer who have failed one or two prior chemotherapeutic regimens. Invest New Drugs. 2011;29:1021-8.

[23] Hainsworth JD, Cebotaru CL, Kanarev V, Ciuleanu TE, Damyanov D, Stella P, et al. A phase II, open-label, randomized study to assess the efficacy and safety of AZD6244 (ARRY-142886) versus pemetrexed in patients with non-small cell lung cancer who have failed one or two prior chemotherapeutic regimens. J Thorac Oncol. 2010;5:1630-6.

[24] Haura EB, Ricart AD, Larson TG, Stella PJ, Bazhenova L, Miller VA, et al. A phase II study of PD0325901, an oral MEK inhibitor, in previously treated patients with advanced non-small cell lung cancer. Clin Cancer Res. 2010;16:2450-7.

[25] O'Neil BH, Goff LW, Kauh JSW, Strosberg JR, Bekaii-Saab TS, Lee R, et al. Phase II study of the mitogen-activated protein kinase $1 / 2$ inhibitor selumetinib in patients with advanced hepatocellular carcinoma. J Clin Oncol. 2011;29:2350-6.

[26] Catalanotti F, Solit DB, Pulitzer MP, Berger MF, Scott SN, lyriboz T, et al. Phase II trial of MEK inhibitor selumetinib (AZD6244, ARRY-142886) in patients with BRAFV600E/K-mutated melanoma. Clin Cancer Res. 2013;19:2257-64.

[27] Long GV, Stroyakovskiy D, Gogas H, Levchenko E, de Braud F, Larkin J, et al. Dabrafenib and trametinib versus dabrafenib and placebo for Val600 BRAF-mutant melanoma: a multicentre, double-blind, phase 3 randomised controlled trial. Lancet. 2015;386:444-51.

[28] Jokinen E, Koivunen JP. MEK and PI3K inhibition in solid tumors: rationale and evidence to date. Ther Adv Med Oncol. 2015;7:170-80.

[29] Gupta A, Love S, Schuh A, Shanyinde M, Larkin JM, Plummer R, et al. DOC-MEK: a double-blind randomized phase II trial of docetaxel with or without selumetinib in wild-type BRAF advanced melanoma. Ann Oncol. 2014;25:968-74.

[30] Janne PA, Smith I, McWalter G, Mann H, Dougherty B, Walker J, et al. Impact of KRAS codon subtypes from a randomised phase II trial of selumetinib plus docetaxel in KRAS mutant advanced non-small-cell lung cancer. Br J Cancer. 2015;113:199-203.

[31] Jänne PA, Mann H, Ghiorghiu D. Study Design and Rationale for a Randomized, PlaceboControlled, Double-Blind Study to Assess the Efficacy and Safety of Selumetinib in Combination With Docetaxel as Second-Line Treatment in Patients With KRAS-Mutant Advanced Non-Small Cell Lung Cancer (SELECT-1). Clin Lung Cancer. 2016;17:e1-4. 
Figure legends

Figure 1.

Phosphorylation of ERK in PBMC lysates following administration of WX-554 and ex-vivo stimulation with PMA. WX-554 was administered in a once- weekly (A. Empty circle, 25 mg. Square, $50 \mathrm{mg}$. Triangle $75 \mathrm{mg}$. Rhombus $100 \mathrm{mg}$. Filled circle $150 \mathrm{mg}$ ), or twice weekly regimen (B. Square, $2 \times 25 \mathrm{mg}$, Rhombus, $2 \times 50 \mathrm{mg}$. Filled circle, $2 \times 75 \mathrm{mg}$ ). Each data point is the mean of the cohort expressed as a percentage of the C1D1 pre-administration sample.

Figure 2.

Modulation of kinase signalling pathways by treatment with WX-554 in paired tumour biopsies from 5 patients in cohort 8 ( $75 \mathrm{mg}$ twice weekly). Known concentrations of biopsy lysates from pre-administration and 8 days post were analysed on MSD electrochemiluminescent assays and phosphorylated protein as a percentage of pre-dose levels expressed as a ratio of un-phosphorylated protein. No change in the phosphorylation as a ratio of total protein (P/T Ratio) of (A) AKT, (B) GSK3 $\beta$, or (C) P70S6K was observed 8 days after the initial dose of WX-554. In contrast, ERK phosphorylation was decreased in $5 / 5$ of the tumour biopsy lysates. Each data point represents the ratio for an individual patient and the line represents the geometric mean at that timepoint

Figure 3.

Pharmacokinetics of WX-554. A \& B) Concentration time curves of the first administration of WX-554 over cycle 1, day 1. WX-554 was administered in a once- weekly (A. Empty circle, 25 $\mathrm{mg}$. Square, $50 \mathrm{mg}$. Triangle $75 \mathrm{mg}$. Rhombus $100 \mathrm{mg}$. Filled circle $150 \mathrm{mg}$ ), or twice weekly regimen (B. Circle, $2 \times 25 \mathrm{mg}$, Square, $2 \times 50 \mathrm{mg}$. Triangle, $2 \times 75 \mathrm{mg}$ ). C \& D) Individual and mean AUC (C) and Cmax (D) on day one. 
Table 1 Patient demographics

\begin{tabular}{|c|c|}
\hline Characteristic & Total patient $(n=41)$ \\
\hline \multicolumn{2}{|l|}{ Age } \\
\hline Median & 63 \\
\hline Range & $36-77$ \\
\hline \multicolumn{2}{|l|}{ Sex } \\
\hline Male & $28(68 \%)$ \\
\hline Female & $13(32 \%)$ \\
\hline \multicolumn{2}{|l|}{ Performance status } \\
\hline 0 & $13(32 \%)$ \\
\hline 1 & $28(68 \%)$ \\
\hline \multicolumn{2}{|l|}{ Number of previous regimens } \\
\hline 0 & 0 \\
\hline 1 & $11(27 \%)$ \\
\hline 2 & 14 (34\%) \\
\hline$>2$ & $16(39 \%)$ \\
\hline \multicolumn{2}{|l|}{ Tumour type } \\
\hline CRC* & $10(24 \%)$ \\
\hline NSCLC & $7(17 \%)$ \\
\hline Mesothelioma & $6(15 \%)$ \\
\hline Oesophageal** & $4(10 \%)$ \\
\hline Pancreatic & $3(7 \%)$ \\
\hline Cholangiocarcinoma & $2(5 \%)$ \\
\hline Cervical & $2(5 \%)$ \\
\hline Gastric & $1(2 \%)$ \\
\hline GIST & $1(2 \%)$ \\
\hline Ampullary carcinoma & $1(2 \%)$ \\
\hline Ovarian & $1(2 \%)$ \\
\hline Adrenocortical & $1(2 \%)$ \\
\hline $\begin{array}{l}\text { Squamous carcinoma of the gall } \\
\text { bladder }\end{array}$ & $1(2 \%)$ \\
\hline Synovial sarcoma & $1(2 \%)$ \\
\hline \multicolumn{2}{|c|}{$\begin{array}{l}\text { *Including } 1 \text { Pouch of Douglas presumed to derive from an anal squamous } \\
\text { carcinoma. ** One squamous carcinoma of the oesophageal gastric junction } \\
\text { and three adenocarcinomas. }\end{array}$} \\
\hline
\end{tabular}




\begin{tabular}{|c|c|c|c|c|c|c|}
\hline & \multirow[b]{2}{*}{ Total } & \multicolumn{5}{|c|}{ Grade } \\
\hline & & 1 & 2 & 3 & 4 & 5 \\
\hline & $\# \quad(\%)$ & $\#(\%)$ & $\#(\%)$ & $\#(\%)$ & $\#(\%)$ & $\#(\%)$ \\
\hline \multicolumn{7}{|l|}{ Most Frequent } \\
\hline Fatigue/Lethargy & $17(43)$ & $3(7)$ & $13(32)$ & $1(2)$ & & \\
\hline Diarrhoea & $15(38)$ & $11(27)$ & $4(10)$ & & & \\
\hline Skin & $11(28)$ & $9(22)$ & $2(5)$ & & & \\
\hline Decreased appetite & $7(18)$ & $4(10)$ & $3(7)$ & & & \\
\hline Nausea & $5(13)$ & $5(12)$ & & & & \\
\hline Vomiting & $5(13)$ & $5(12)$ & & & & \\
\hline Abdominal Pain & $4(10)$ & $3(7)$ & $1(2)$ & & & \\
\hline \multicolumn{7}{|l|}{ SAE } \\
\hline ALT Increased & & & & & $1(2)$ & \\
\hline Anaemia & & & & & $1(2)$ & \\
\hline AST Increased & & & & $1(2)$ & & \\
\hline Bowel perforation & & & & & $1(2)$ & \\
\hline Prolonged QTC & & & $1(2)$ & & & \\
\hline
\end{tabular}




\begin{tabular}{|c|c|c|c|c|c|c|c|c|c|c|c|c|c|c|}
\hline \multirow{3}{*}{ Frequency } & \multirow{3}{*}{$\begin{array}{l}\text { Dose } \\
(\mathrm{mg})\end{array}$} & \multirow{3}{*}{$\begin{array}{c}\text { Cohort size } \\
\text { (n) }\end{array}$} & \multicolumn{10}{|c|}{ Table 3) Pharmacokinetic parameters during dose escalation of WX-554 } & \multirow{2}{*}{\multicolumn{2}{|c|}{$\begin{array}{c}\mathrm{AUC} \mathrm{C}_{\text {inf }} \\
\left(\mathrm{h}^{*} \mathrm{ng} / \mathrm{ml}\right)\end{array}$}} \\
\hline & & & \multicolumn{2}{|c|}{$\begin{array}{l}\mathrm{t}_{1 / 2} \\
(\mathrm{~h})\end{array}$} & \multicolumn{2}{|c|}{$\begin{array}{l}\mathrm{T}_{\max } \\
(\mathrm{h})\end{array}$} & \multicolumn{2}{|c|}{$\begin{array}{c}\mathrm{C}_{\max } \\
(\mathrm{ng} / \mathrm{ml})\end{array}$} & \multicolumn{2}{|c|}{$\begin{array}{l}\mathrm{Vz} / \mathrm{F} \\
(\mathrm{L})\end{array}$} & \multicolumn{2}{|c|}{$\begin{array}{c}\mathrm{Cl} / \mathrm{F} \\
(\mathrm{ml} / \mathrm{min})\end{array}$} & & \\
\hline & & & Mean & (SD) & Mean & (SD) & Mean & (SD) & Mean & (SD) & Mean & (SD) & Mean & (SD) \\
\hline & & & & & & & Day 1 & & & & & & & \\
\hline & 25 & 3 & 20.0 & $(2.5)$ & 4.7 & (1.2) & 10.2 & (1.6) & 3096.4 & (604.8) & 1781.1 & $(228.3)$ & 236.4 & (28.9) \\
\hline & 50 & $3^{a}$ & 14.8 & (4.7) & 6.0 & (2.0) & 16.7 & (2.5) & 3026 & (342.0) & 2529.8 & (1076.2) & 362.2 & (154.1) \\
\hline \multirow[t]{3}{*}{ QWK } & 75 & 6 & 27.4 & $(13.5)$ & 5.7 & (1.5) & 23.5 & (10.8) & 3502.4 & (1923.5) & 2273.6 & (2247.7) & 1259.1 & (1024.5) \\
\hline & 100 & 6 & 19.0 & $(8.2)$ & 4.7 & (2.1) & 29.2 & $(9.2)$ & 4199.5 & $(2619.7)$ & 2836.3 & (1641.4) & 859.8 & (706.07) \\
\hline & 150 & 6 & 27.5 & (8.6) & 4.2 & (2.6) & 64.8 & (27.6) & 3104.6 & (1568.4) & 1512.3 & $(1649.6)$ & 3104.6 & (1924.9) \\
\hline \multirow[t]{2}{*}{ Bis } & 50 & 3 & 50.1 & $(29.5)$ & 4.7 & (3.1) & 12.2 & (2.9) & 4573.5 & (1275.9) & 1211.9 & (435.9) & 746.2 & $(248.7)$ \\
\hline & 75 & 9 & 22.4 & (19.7) & 4.2 & (1.2) & 20.3 & (9.4) & 4804 & (2313.7) & 3257.3 & $(1458.0)$ & 631.9 & (760.4) \\
\hline \multicolumn{15}{|c|}{ Day 8} \\
\hline \multirow{6}{*}{ QWK } & 25 & 3 & 21.5 & (5.3) & 4.0 & (3.5) & 9.9 & $(0.5)$ & 2937.3 & (470.3) & 1618.3 & (331.8) & 265.1 & (56.4) \\
\hline & 50 & 3 & 18.1 & (1.9) & 4.7 & (1.2) & 18.1 & (1.0) & 2641.6 & (402.4) & 1698.7 & (365.9) & 504.5 & (97.2) \\
\hline & 75 & $6^{c}$ & 30.9 & $(14.8)$ & 6.0 & $(2.2)$ & 25.9 & (12.3) & 2911.8 & (897.3) & 1689.4 & (1618.2) & 1366.2 & (912.7) \\
\hline & 100 & 6 & 22.9 & $(11.8)$ & 4.3 & (1.5) & 32.3 & (18.7) & 5885 & $(6711.5)$ & 2728.8 & (1572.9) & 958.4 & (895.5) \\
\hline & 150 & 6 & 27.7 & $(9.2)$ & 5.3 & (3.0) & 70.8 & (31.6) & 2387.2 & $(1402.4)$ & 1442.5 & (1771.5) & 3598.9 & (2384.6) \\
\hline & 25 & $3^{d}$ & 75.0 & $(16.2)$ & 5.3 & (1.2) & 4.5 & $(2.5)$ & 11054.8 & (7316.2) & 1869.1 & (1531.6) & 335.6 & $(275.0)$ \\
\hline Bis & 75 & 9 & 18.6 & $(10.0)$ & 3.4 & (1.8) & 21.9 & (9.9) & 4094.4 & (1758.3) & 3119.5 & (1906.6) & 605.7 & (458.8) \\
\hline
\end{tabular}

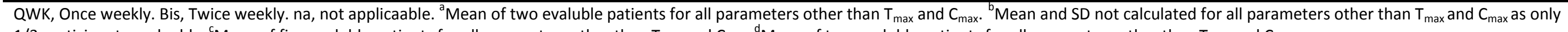
$1 / 3$ participants evaluable. ${ }^{c}$ Mean of five evaluble patients for all parameters other than $T_{\max }$ and $C_{\max }{ }^{d}$ Mean of two evaluble patients for all parameters other than $T_{\max }$ and $C_{\max }$. 
Figure 1
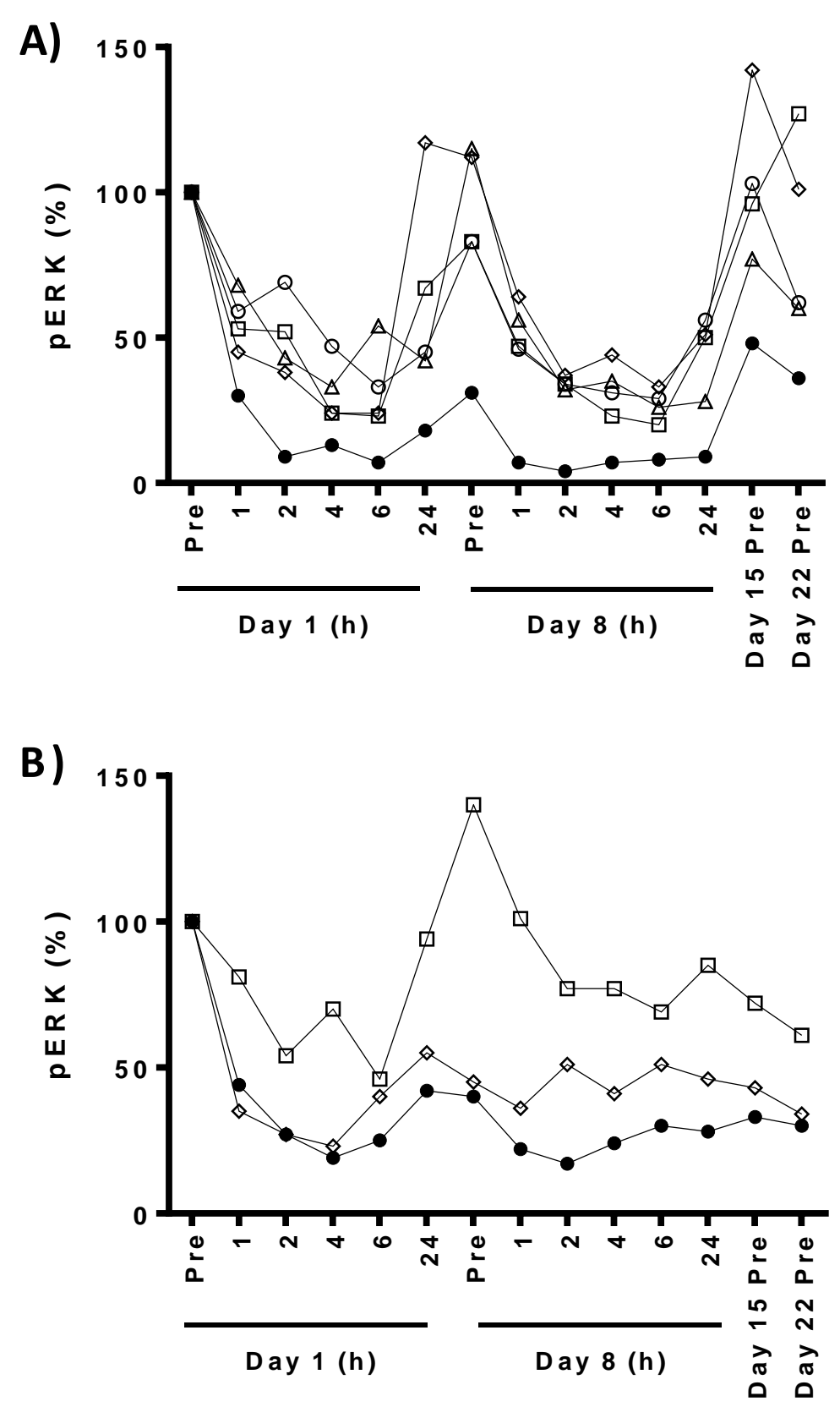
Figure 2
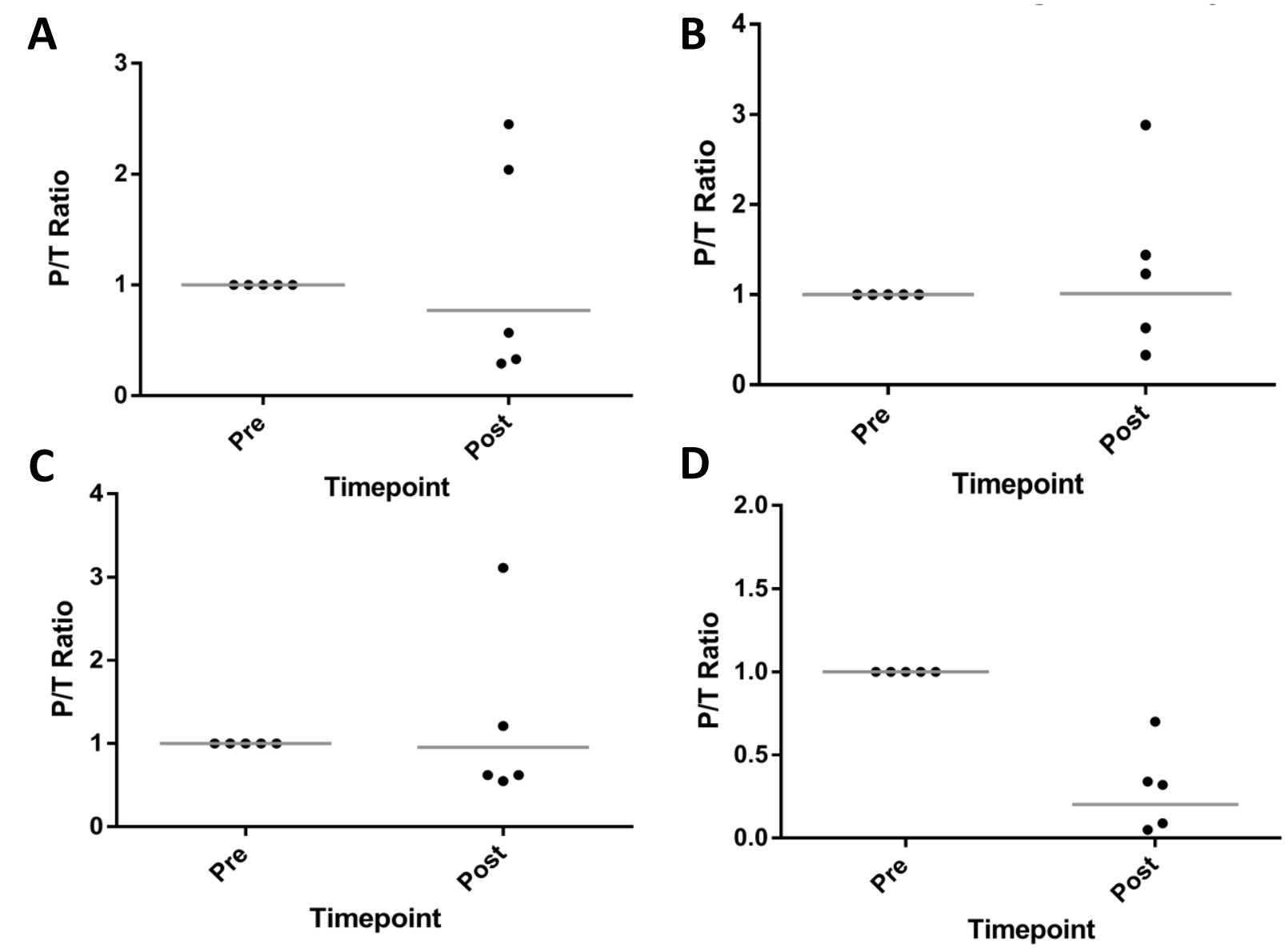
Figure 3
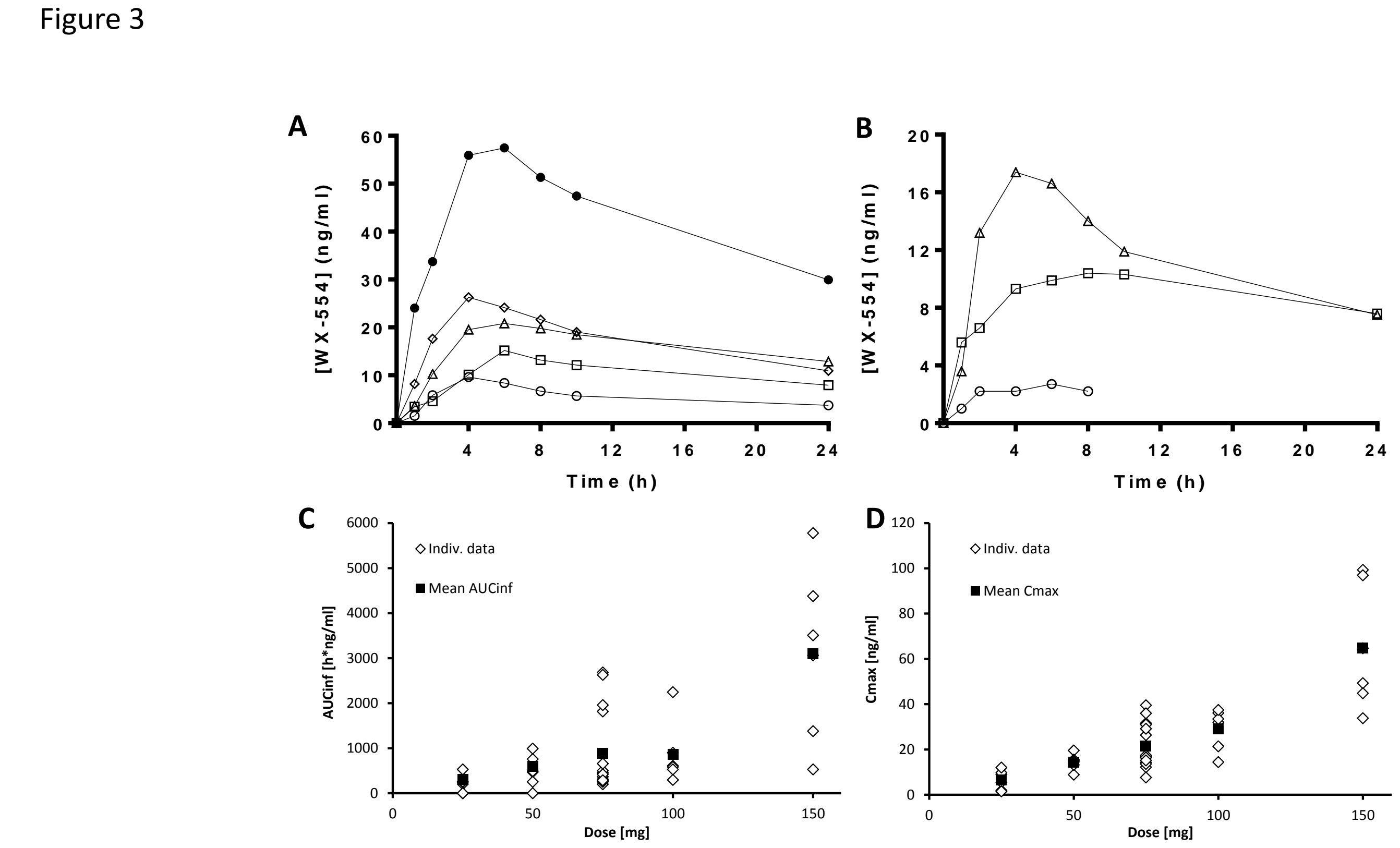
A Phase I pharmacokinetic and pharmacodynamic study of the oral MEK inhibitor, WX554 , in patients with advanced solid tumours.

David Jamieson, Melanie J Griffin, Julieann Sludden, Yvette Drew ${ }^{\mathrm{b}}$, Nicola Cresti, Karen Swales, Mark Merriman, Rodger Allen, Paul Bevan, Markus Buerkle, Carola Mala, Vicky Coyle, Lisa Rodgers, Emma Dean, Alastair Greystoke, Udai Banerji, Richard H Wilson, TR Jeffry Evans, Alan Anthoney, Malcolm Ranson, Alan V Boddy, Ruth Plummer*

Potential conflicts of interest:

P Bevan, M Buerkle and Carola Mala were employees of Wilex AG who were developing WX554 during the study. Mark Merriman and Rodger Allen are employees of UCB who now own the rights for further development of WX-554. 
A Phase I pharmacokinetic and pharmacodynamic study of the oral MEK inhibitor, WX554 , in patients with advanced solid tumours.

David Jamieson, Melanie J Griffin, Julieann Sludden, Yvette Drew ${ }^{b}$, Nicola Cresti, Karen Swales, Mark Merriman, Rodger Allen, Paul Bevan, Markus Buerkle, Carola Mala, Vicky Coyle, Lisa Rodgers, Emma Dean, Alastair Greystoke, Udai Banerji, Richard H Wilson, TR Jeffry Evans, Alan Anthoney, Malcolm Ranson, Alan V Boddy, Ruth Plummer*

Supplementary material 
Figure S1

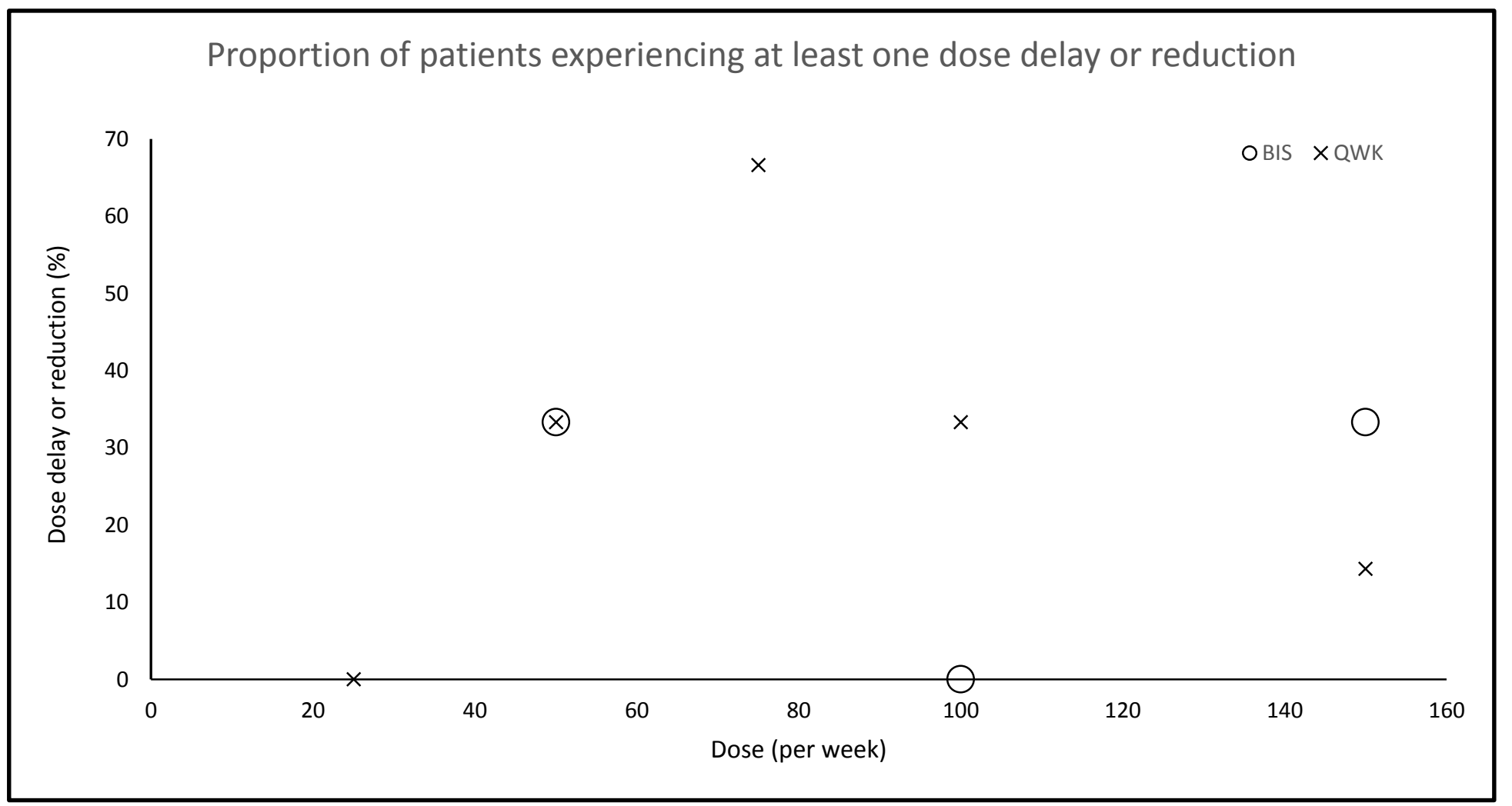



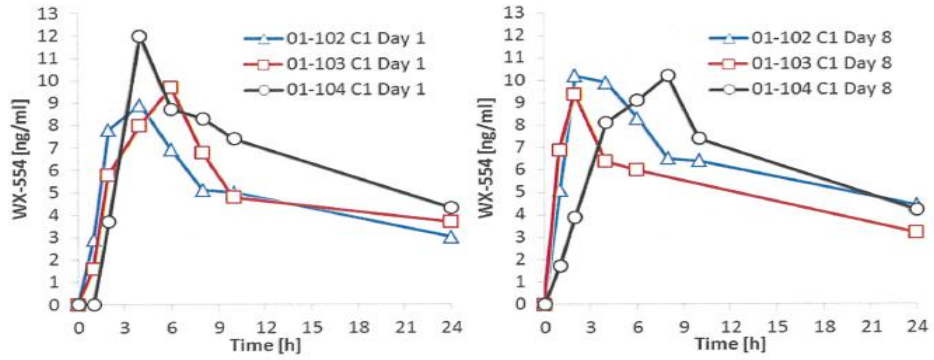

Plasma concentration time profiles on day 1 and day 8 after

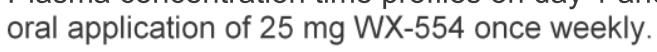
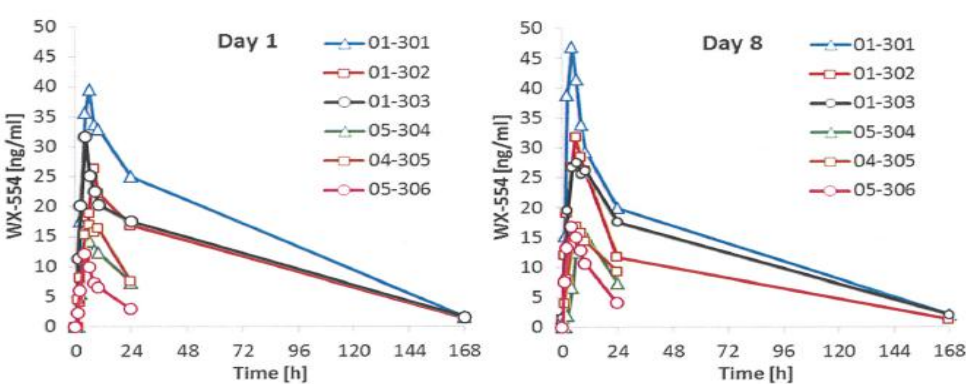

Plasma concentration time profiles on day 1 and day 8 after oral

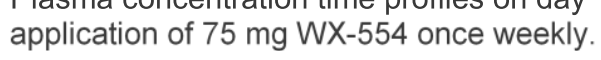
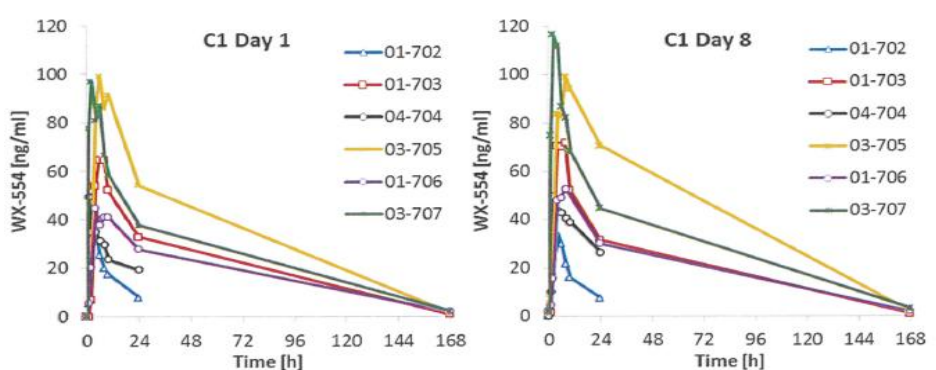

Plasma concentration time profiles on day 1 and day 8 after

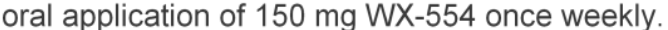

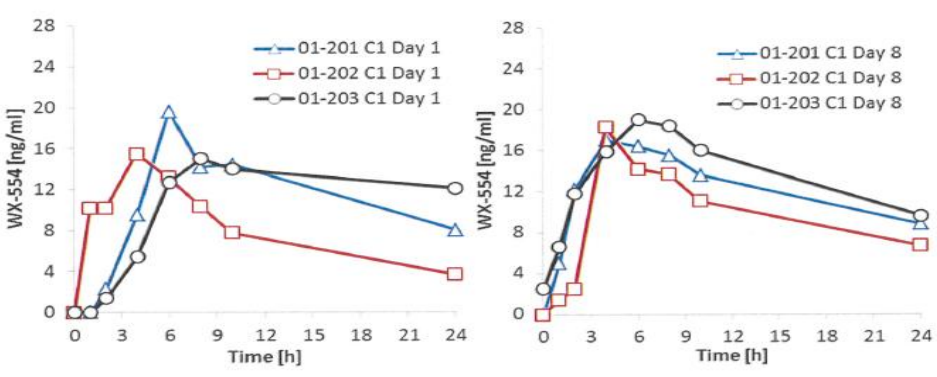

Plasma concentration time profiles on day 1 and day 8 after

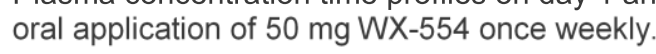
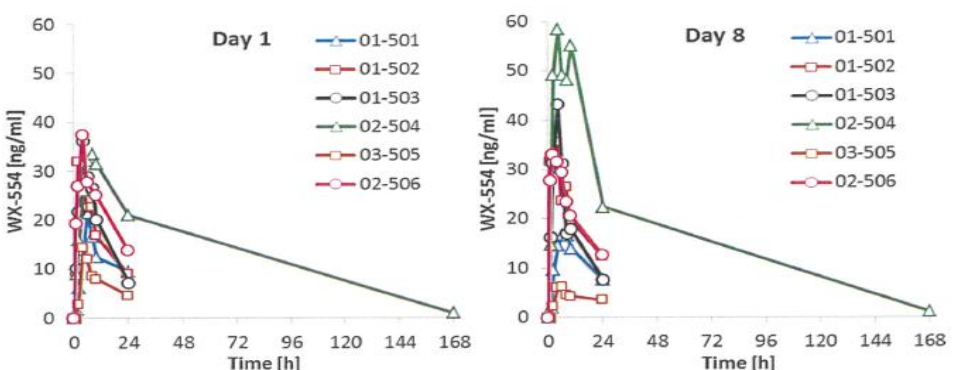

Plasma concentration time profiles on day 1 and day 8 after

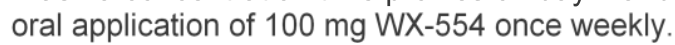


Figure S2

(cont.)
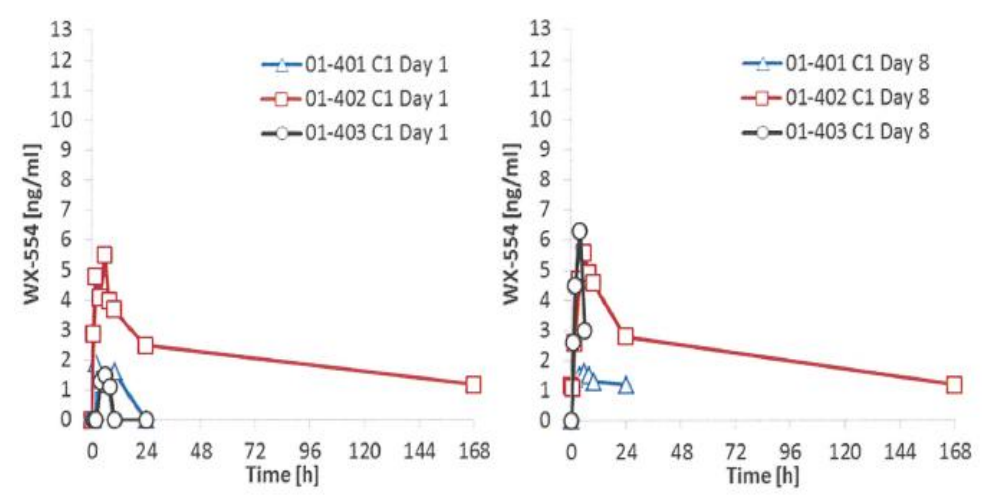

Plasma concentration time profiles on day 1 and day 8 after oral application of $25 \mathrm{mg} \mathrm{WX-554}$ twice weekly
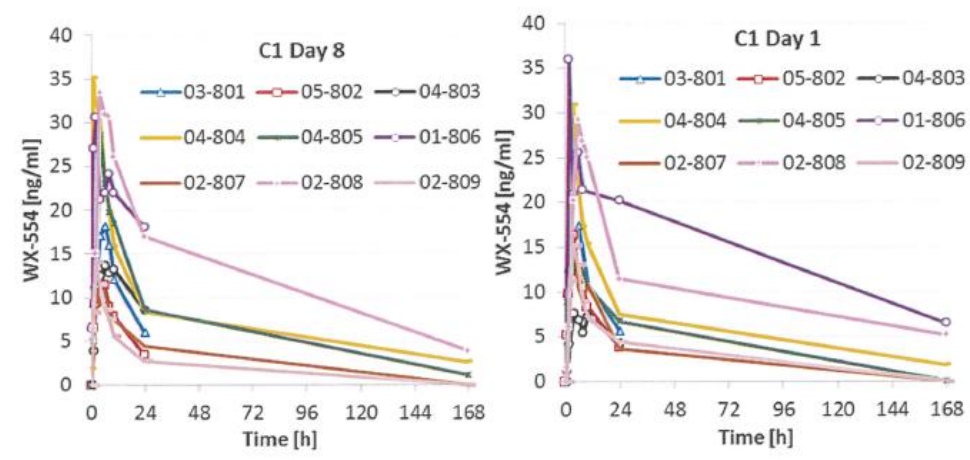

Plasma concentration time profiles on day 1 and day 8 after oral application of $75 \mathrm{mg} \mathrm{WX-554}$ twice weekly
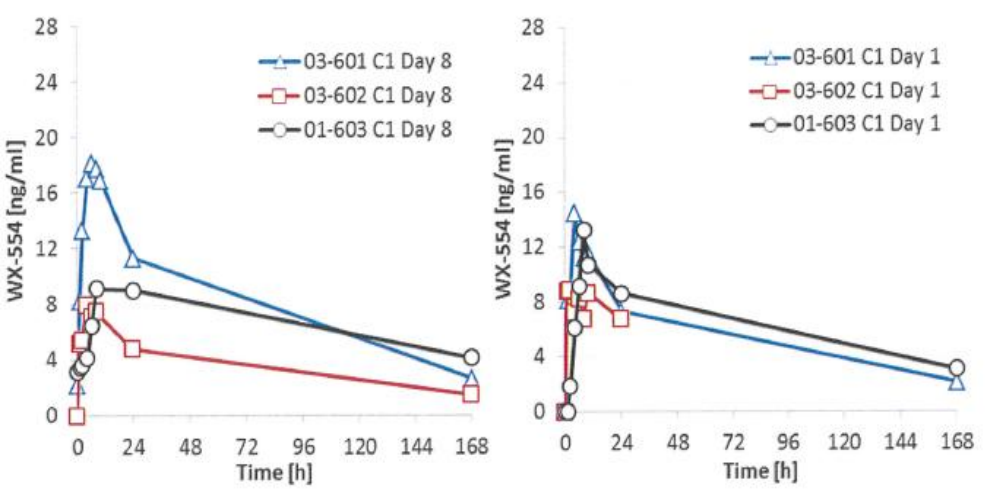

Plasma concentration time profiles on day 1 and day 8 after oral application of $50 \mathrm{mg} \mathrm{WX-554}$ twice weekly 
Table S1

Table S1) Study participants and cohort size

\begin{tabular}{ccc} 
Cohort & Participants (\#) & WX-554 (mg/wk) \\
\hline 1 & $4^{*}$ & 25 \\
2 & 3 & 50 \\
3 & 6 & 75 \\
4 & 3 & $2 \times 25$ \\
5 & 6 & 100 \\
6 & 3 & $2 \times 50$ \\
7 & 7 & 150 \\
8 & 9 & $2 \times 75$ \\
\hline
\end{tabular}

*One participant in cohort 1 developed fatal bronchopneumonia prior to the first administration of WX-554 and the cohort was extended to 4 participants. 
Table S2) Incidence of participants with at least one adverse events for each cohort

\begin{tabular}{|c|c|c|c|c|c|c|c|c|c|c|c|c|c|c|c|c|c|c|}
\hline \multicolumn{19}{|c|}{ WX-554 administered (mg) } \\
\hline & \multicolumn{2}{|c|}{25} & \multicolumn{2}{|r|}{50} & \multicolumn{2}{|c|}{75} & \multicolumn{2}{|c|}{100} & \multicolumn{2}{|c|}{150} & \multicolumn{2}{|c|}{$2 \times 25$} & \multicolumn{2}{|c|}{$2 \times 50$} & \multicolumn{2}{|c|}{$2 \times 75$} & \multicolumn{2}{|r|}{ Total } \\
\hline & $\#$ & (\%) & $\#$ & (\%) & $\#$ & (\%) & $\#$ & (\%) & $\#$ & (\%) & $\#$ & (\%) & \# & $(\%)$ & $\#$ & (\%) & $\#$ & $(\%)$ \\
\hline Fatigue/lethargy & 1 & (33.3) & 1 & $(33.3)$ & 4 & $(66.7)$ & 3 & (50) & 4 & (57.1) & 2 & (66.7) & 3 & $(100)$ & 7 & $(77.8)$ & 25 & $(62.5)$ \\
\hline Diarrhoea & 1 & $(33.3)$ & 1 & $(33.3)$ & 3 & (50) & 4 & $(66.7)$ & 5 & $(71.4)$ & 1 & (33.3) & 1 & $(33.3)$ & 2 & $(22.2)$ & 18 & $(45)$ \\
\hline Nausea & & & 1 & (33.3) & 5 & (83.3) & 2 & (33.3) & 2 & $(28.6)$ & 1 & (33.3) & 1 & (33.3) & 4 & (44.4) & 16 & $(40)$ \\
\hline Skin & 1 & (33.3) & & & 2 & (33.3) & 3 & (50) & 4 & (57.1) & 2 & $(66.7)$ & 1 & (33.3) & 3 & (33.3) & 16 & $(40)$ \\
\hline Vomiting & & & 1 & $(33.3)$ & 5 & $(83.3)$ & 2 & (33.3) & 1 & $(14.3)$ & 1 & (33.3) & 1 & (33.3) & 3 & (33.3) & 14 & (35) \\
\hline Decreased appetite & & & & & 3 & (50) & & & 2 & $(28.6)$ & 2 & (66.7) & 2 & $(66.7)$ & 4 & (44.4) & 13 & $(32.5)$ \\
\hline Abdominal Pain & 1 & (33.3) & 1 & (33.3) & 3 & (50) & & & & & 1 & (33.3) & 2 & $(66.7)$ & 4 & (44.4) & 12 & $(30)$ \\
\hline Infection & 1 & (33.3) & 1 & (33.3) & 5 & (83.3) & 1 & $(16.7)$ & & & 1 & (33.3) & & & 2 & $(22.2)$ & 11 & $(27.5)$ \\
\hline Constipation & & & 1 & (33.3) & 2 & (33.3) & 2 & (33.3) & 1 & $(14.3)$ & 2 & (66.7) & & & 1 & (11.1) & 9 & $(22.5)$ \\
\hline Anaemia & & & 1 & (33.3) & 2 & (33.3) & & & 2 & $(28.6)$ & 1 & (33.3) & 1 & (33.3) & 1 & (11.1) & 8 & (20) \\
\hline Dyspnoea & 1 & (33.3) & & & 2 & (33.3) & & & 1 & (14.3) & 1 & (33.3) & & & 3 & (33.3) & 8 & $(20)$ \\
\hline ALP Increased & & & & & 1 & (16.7) & 1 & (16.7) & 1 & (14.3) & 1 & (33.3) & & & 2 & $(22.2)$ & 6 & (15) \\
\hline Cough & & & & & 2 & (33.3) & 1 & (16.7) & 1 & $(14.3)$ & 1 & (33.3) & & & 1 & (11.1) & 6 & (15) \\
\hline ALT Increased & & & & & 1 & $(16.7)$ & 1 & (16.7) & 1 & $(14.3)$ & 1 & (33.3) & & & 1 & (11.1) & 5 & $(12.5)$ \\
\hline Bilirubin & & & & & 1 & (16.7) & 1 & (16.7) & 1 & (14.3) & & & & & 2 & (22.2) & 5 & (12.5) \\
\hline Dyspepsia & & & 1 & (33.3) & 1 & (16.7) & & & 1 & (14.3) & & (0) & 1 & (33.3) & 1 & (11.1) & 5 & (12.5) \\
\hline AST Increased & & & & & 1 & $(16.7)$ & 1 & (16.7) & & & 1 & (33.3) & & & 1 & (11.1) & 4 & (10) \\
\hline CRP increased & & & & & & & & & 1 & $(14.3)$ & 1 & (33.3) & & & 2 & $(22.2)$ & 4 & $(10)$ \\
\hline
\end{tabular}

